\title{
Major Differences in Hypoxia Tolerance and P38 Regulation Among Different Renal Cells
}

\author{
Qianqian Shi ${ }^{a}$ Jian Shia Fengbao Luo ${ }^{a}$ Guanglai Song ${ }^{a} \quad$ Xiaozhou He \\ Ying Xiab
}

aDepartment of Urology, The Third Affiliated Hospital of Soochow University, Changzhou, Jiangsu, bShanghai Key Laboratory of Acupuncture Mechanism and Acupoint Function; Department of Aeronautics and Astronautics, Fudan University, Shanghai, China

\section{Key Words}

Mitogen-activated protein kinases $•$ ERK1/2 $・$ P38 $•$ EEF2k $・$ Kidney $・$ Hypoxia

\begin{abstract}
Background/Aims: Mitogen-activated protein kinases (MAPKs) are involved in the cellular response to hypoxia and their dysregulation may contribute to the progression and pathology of diverse human renal diseases. Recent studies suggest that the regulation of MAPK responses to hypoxic stress may be different in different cells, even within the same organ. However, it is unclear if MAPKs are differentially regulated in different renal cells in hypoxia. This work was carried out to clarify this fundamental issue. Methods: We cultured normal rat kidney epithelial (NRK-52E) cells, human kidney epithelial (HK-2) cells and human renal cell adenocarcinoma (769-P) cells simultaneously under normoxia and hypoxia $\left(1 \% \mathrm{O}_{2}\right)$ for $24-72$ hours. The protein levels of P-ERK1/2, ERK1/2, P-p38, p38 and eEF2K were detected by western blotting. The morphology of all cells was examined using light microscopy. Results: Under the same hypoxic condition, P-ERK1/2 was up-regulated in all renal cells. Meanwhile,P-p38 in NRK-52E cells was markedly increased after hypoxia for 24-72 hours, while it appeared to show no appreciable change in HK-2 and 769-P cells exposed to hypoxia for 24-48 hours and significantly decreased in these cells after 72 hours hypoxia. On the other hand,hypoxia markedly down-regulated the expression of eukaryotic elongation factor- 2 kinase (eEF2K) in all three cells. Under microscopy, NRK-52E cells had no visible injury after 72 hours hypoxia, while HK-2 and 769-P cells were mostly damaged under the same condition. Conclusions: Our data suggest that in response to prolonged hypoxic stress, ERK1/2 and p38 are differentially regulated in three renal cells, while eEF2K is largely down-regulated in all of these cells.
\end{abstract}

\section{Introduction}

More than 500 million people worldwide suffer from varying degrees of kidney diseases including acute/chronic renal dysfunction and renal carcinoma. Although there are many causes attributed to the renal pathophysiology, hypoxia is one of the common clinical problems that has profound effects on renal homeostasis [1]. Indeed, the kidney is, like the

Ying Xia, M.D., Ph.D.

and Xiaozhou He, M.D. 
brain and heart, very sensitive to hypoxic/ischemic stress. Hypoxia is implicated as one of the major causes of acute kidney injury and chronic kidney diseases [2]. In renal tubular epithelial cells, for instance, hypoxia can lead to abnormal metabolism, biochemical disorders, and eventually renal dysfunction and structural damage, leading to serious renal diseases. Moreover, renal cancer, like most other solid cancers, creates a hypoxic microenvironment that affects the progress and treatment of these cancers. Therefore, it is of great importance to better understand hypoxic pathophysiology of the kidney and the underlying molecular mechanisms.

Hypoxic stress can activate or inactivate multiple signaling pathways, leading to cell differentiation, proliferation, migration and apoptosis [3]. Among many signaling molecules, Mitogen-activated protein kinases (MAPKs) are early responders to insufficient oxygen. They are made up of four well-described subgroups, i.e.,the extracellular signal-regulated kinases-1 and -2 (ERK1/2), the c-Jun N-terminal kinases (JNK), p38 MAPKs, and extracellular signalregulated kinase-5 (ERK5/BMK1) [4-6]. In general, ERK1/2 is relevant to cell proliferation/ survival, while p38 is associated with cell apoptosis [7-13]. They usually present opposite changes in response to hypoxic and/or ischemic stress. Interestingly, our recent work has shown that in normal rat kidney epithelial cells (NRK-52E cells), both ERK1/2 and p38 phosphorylation (P-ERK1/2 and P-p38) remarkably increased after prolonged hypoxia ENREF_6[14, 15]. This notion is very different from what we have seen in the neurons [16].

We therefore wondered whether this MAPK response is a unique change in the particular renal cells or a universal response to hypoxia in various renal cells. To clarify this fundamental issue, we simultaneously culturedNRK-52E cells, human kidney epithelial (HK2 ) cells and human renal cell adenocarcinoma (769-P) under the same conditions and then compared the expression of ERK1/2 and p38 from the same culture sample at varying time points of hypoxic duration. In order to verify the specificity of ERK1/2 and p38 changes in these cells, we determined the expression of eukaryotic elongation factor-2 kinase (eEF2K), which is highly conserved among eukaryotes from mammals to invertebrates and varies under environmental metabolic stresses, including hypoxia, nutrient deprivation, and growth factor deprivation [17]. Our results show that hypoxia differentially alters ERK1/2 and p38 in different renal cells and gravely suppresses eEF2K expression in all renal cells studied.

\section{Materials and Methods}

\section{Antibodies and Reagents}

The antibodies for P-ERK1/2, ERK1/2, P-p38, p38 and eEF2K were purchased from Cell Signaling Technology (Beverly, MA, USA). All cell culture media and other reagents were purchased from Thermo Fisher Scientific Inc. (Waltham, MA, USA). Western blot reagents were purchased from Beyotime Biotechnology (Shanghai, China).

\section{Cell culture, hypoxic conditions}

The NRK-52E, HK-2, and 769-P cells were purchased from the Chinese Academy of Sciences Cell Bank (Shanghai, China). NRK-52E cells were cultured in Dulbecco's Modified Eagle's medium (DMEM), supplemented with $5 \%(\mathrm{v} / \mathrm{v})$ fetal bovine serum and $1 \%$ penicillin/streptomycin, while HK-2 and 769-P cells were incubated in RPMI 1640 Medium, supplemented with $10 \%$ fetal bovine serum and $1 \%$ penicillin/ streptomycin. The cells were maintained at $37^{\circ} \mathrm{C}$ in an incubator (Thermo Fisher Scientific Inc., Waltham, MA, USA)with humidified atmosphere containing $5 \% \mathrm{CO}_{2} / 95 \%$ air. Prior to experimental procedures, the cells were grown to 70-80 \% confluence, then were transferred into a triple gas incubator. To induce hypoxia, nitrogen gas was flushed into the incubator to bring the oxygen content down to $1 \%$ with the carbon dioxide content being at $5 \%$. All cells were cultured in either normoxia (ambient oxygen) or hypoxia $\left(1 \% \mathrm{O}_{2}\right)$ for 24,48 or 72 hours.

\section{KARGER}




\section{Cellular Physiology Cell Physiol Biochem 2018;46:1483-1492 \begin{tabular}{l|l} 
and Biochemistry & DOI: 10.1159/000489188 \\
Published 2018 The Author(s). Published by S. Karger AG, Basel \\
www.karger.com/cpb
\end{tabular}

\section{Western Blot Analysis}

The cells were seeded in $25-\mathrm{cm}^{2}$ culture flasks. Following treatment(s), the cells were collected, centrifuged, washed twice in ice-cold PBS and whole-cell lysates were obtained by suspending the cells in a lysis buffer at $4^{\circ} \mathrm{C}$. Proteins were extracted from cell lysates. The total protein concentration was measured using a BCA assay kit according to the manufacturer's instructions and the equivalent of thirty micrograms of protein were subjected to SDS-PAGE. The proteins were separated at $100 \mathrm{~V}$ for approximately 2 hours. After electrophoresis, the wet sandwich was assembled and the proteins were transferred onto a PVDF membrane (Thermo Fisher Scientific Inc., Waltham, MA, USA) at $350 \mathrm{~mA}$ for 1 hour. After the transfer, the membrane was blocked with 5\% dry low-fat milk in Tris-buffered saline with Tween 20 (TBST) for 60 min at room temperature. Subsequently, the membranes were incubated with rabbit anti-P-ERK1/2, anti-ERK1/2, anti-P-p38, anti-p38 and anti-eEF2K antibodies, respectively, at the concentration of 1:1000 overnight. The membranes were then washed with TBST for three times, and incubated with HRP-conjugated goat antirabbit IgG secondary antibody at 1:2000 for 2 hours at room temperature. The signals were detected with enhanced chemiluminescence Western blotting detection reagents (Pierce) according to the manufacturer. Image Quantity One software (Bio-Rad, Hercules, CA, USA) was used for quantification of the relative abundance of proteins.

\section{Statistical Analysis}

All experiments were repeated in independent sets of work for at least three times ( $\mathrm{n}=3$ or more). The results are presented as mean \pm standard deviation (SD).All statistical analyses were performed using Student's t test by GraphPad Prism statistical software. The statistical level of significance was defined as $\mathrm{p}<0.05$.

\section{Results}

Major differences in ERK1/2 response to hypoxia among different renal cells

We have recently shown a major increase in P-ERK1/2 in NRK-52E cells [14]. To determine whether this is a unique response of NRK-52E cells to hypoxia, or a general change in various renal cells exposed to hypoxia, we simultaneously compared NRK-52E, HK-2 and 769-P cells in terms of their ERK1/2 response to hypoxic stress. As shown in Fig. 1a, the level of P-ERK1/2 was up-regulated by 1-3 fold $(\mathrm{P}<0.05)$ in NRK-52E cells after hypoxia for 24 hours, 48 hours or 72 hours. In HK-2 and 769-P cells (Fig. 1b, c), however, P-ERK1/2 did not induce any significant change after 24 hours hypoxia, but it increased by 3 fold after 48 hours hypoxia. In sharp contrast to the NRK-52E cells, 72 hours hypoxia induced a significant decrease in P-ERK1/2 with major cell injury. When compared to the control level, P-ERK1/2 was decreased by $70 \%$ after 72 hours hypoxia. In all these cells, the total ERK1/2 showed no appreciable changes after 24-72 hours of hypoxia. These results suggest that different renal cells differentially respond to hypoxic stress in terms of ERK1/2 phosphorylation and cell survival.

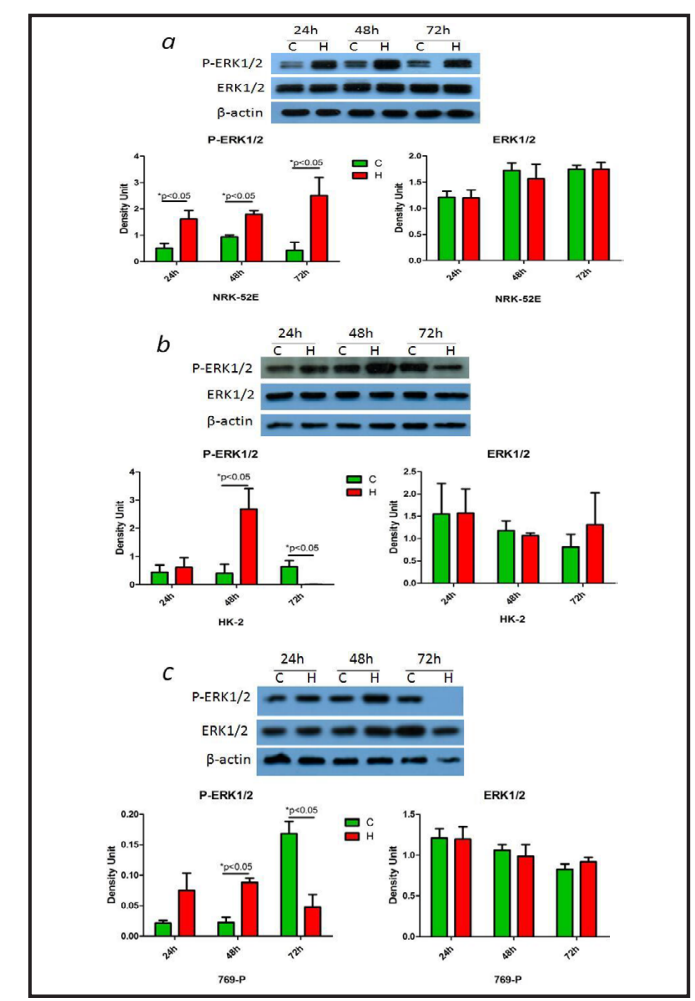

Fig. 1. Effect of hypoxia on P-ERK1/2 and ERK1/2 in NRK-52E cells (a), HK-2 cells (b) and 769-p cells (c). The hypoxic cells were cultured in a hypoxic incubator at $1 \% \mathrm{O}_{2}$ for 24,48 or $72 \mathrm{hrs}$. C: control (normoxia). H: hypoxia. Upper panel: The P-ERK1/2 and total ERK1/2 responses to hypoxia for 24, 48 and $72 \mathrm{hrs}$. Lower panel: Densitometric analysis of P-ERK1/2 and total ERK1/2 signal bands in both normoxic and hypoxic groups. ${ }^{*} \mathrm{p}<0.05$ vs. Control. $\mathrm{n}=3$ /group. 


\section{Major differences in 18 response to hypoxia among different renal cells}

P38 oftentimes appears to oppose ERK1/2 function and is frequently linked to the process of inflammation and apoptosis [18]. In NRK-52E cells, P-p38 was substantially upregulated after exposure to hypoxia at 24,48 or 72 hours (17). Since the ERK1/2 response to hypoxia is different in three kinds of renal cells, we further investigated whether P-p38 is differentially regulated in these renal cells in response to hypoxia. Surely enough, P-p38 in NRK-52E cells increased by 2 fold $(\mathrm{P}<0.05)$ at all time points of hypoxia, in comparison with corresponding normoxia groups (Fig. 2a), which is consistent with our previous observation (17). However, in HK-2 and 769-P cells under the same experimental conditions, the level of P-p38 did not change significantly after 24-48 hours of hypoxic stress, while largely decreasing after 72 hour of hypoxia (Fig. 2b, c), which is in sharp contrast to NRK-52E cells. No appreciable changes were observed in the levels of total p38 among all these cells. These data suggest that the regulation of P-p38 is also different among various renal cells.

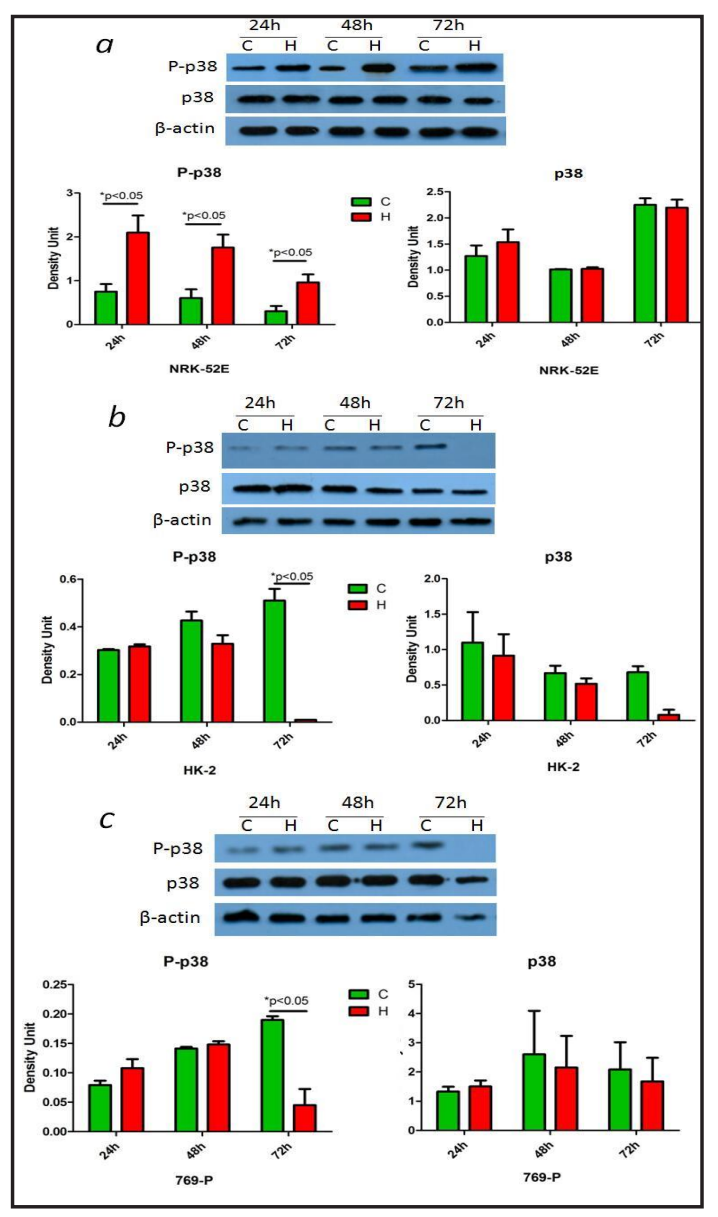

Fig. 2. Effect of hypoxia on P-p38 and p38 in NRK52E cells (a), HK-2 cells (b) and 769-p cells (c). The hypoxic cells were cultured in a hypoxic incubator at $1 \% \mathrm{O}_{2}$ for 24,48 or $72 \mathrm{hrs}$. C: control (normoxia). H: hypoxia. Upper panel: The P-p38 and total p38 responses to hypoxia for 24, 48 and $72 \mathrm{hrs}$. Lower panel: Densitometric analysis of P-p38 and total p38 signal bands in both normoxic and hypoxic groups. ${ }^{*} \mathrm{p}<0.05$ vs. Control. $\mathrm{n}=4$ /group.
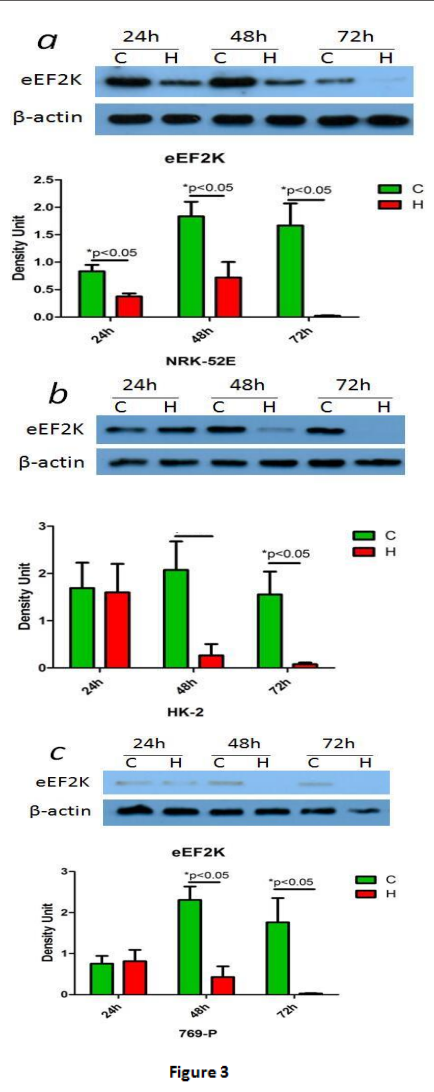

Fig. 3. Effect of hypoxia on eEF2K in NRK-52E cells (a), HK-2 cells (b) and 769-p cells (c).The hypoxic cells were cultured in a hypoxic incubator at $1 \% \mathrm{O}_{2}$ for 24,48 or 72 hrs. C:control (normoxia). H: hypoxia. Upper panel: The eEF2K expression in normoxic and hypoxic conditions for 24, 48 or $72 \mathrm{hrs}$. Lower panel: Densitometric analysis of eEF2K signal bands in both normoxic and hypoxic groups. ${ }^{*} \mathrm{p}<0.05$ vs. Control. $\mathrm{n}=3$ /group. 


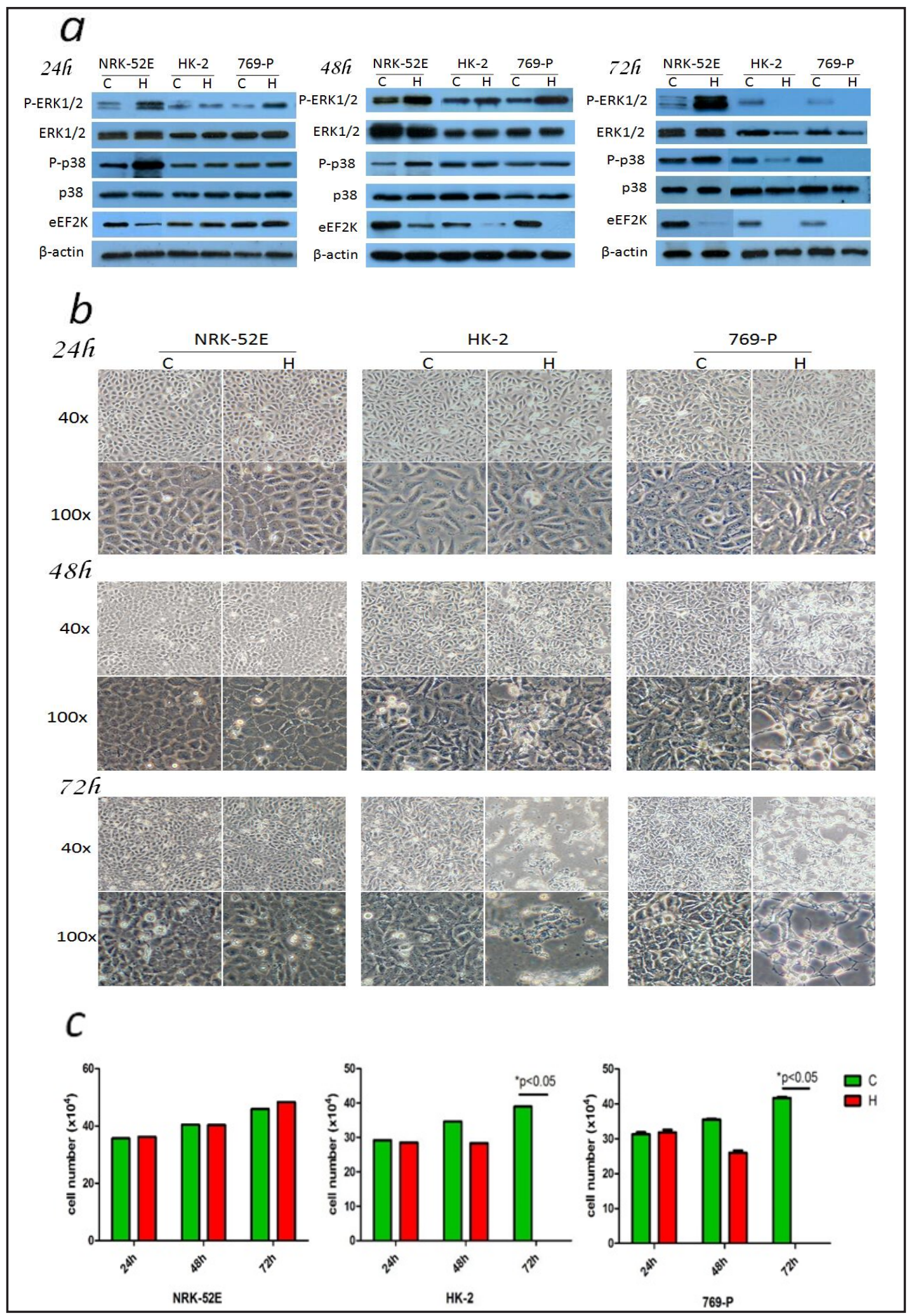

Fig. 4. Different cells appear to have different tolerance to hypoxia. a: Western blot of P-ERK1/2, ERK1/2, P-p38, p38, eEF2K. b: Microscope view of NRK-52E, HK-2 and 769-P (magnification, 40X, 100X). c: The quantification of cell numbers. Statistic analysis of cell numbers in both normoxic and hypoxic groups. ${ }^{*} \mathrm{p}<0.05$ vs. Control. $\mathrm{n}=4$ /group.

\section{KARGER}




\section{A major difference in eEF2K vs. MAPK responses to hypoxia}

To further verify the characteristic changes in ERK1/2 and p38 in response to hypoxic stress in the renal cells, we detected another kinase, eEF2K, in terms of its response to hypoxia. It was chosen because it acts as a negative modulator of protein synthesis, and has a critical function during stressful conditions, such as hypoxia, nutrient deprivation and growth factor inhibition [19]. The results showed that prolonged hypoxia greatly reduced the expression of eEF2k in NRK-52E cells. When compared with the control, eEF2K decreased to $50 \%(\mathrm{P}<0.05), 50 \%(\mathrm{P}<0.05)$, and $90 \%(\mathrm{P}<0.05)$ of the control level after 24 hours, 48 hours and 72 hours hypoxia, respectively (Fig. 3a). A similar trend was also observed in two other kinds of renal cells with even larger decreases. In HK-2 cells, eEF2K expression was down-regulated by $85 \%(\mathrm{P}<0.05)$ and $80 \%(\mathrm{P}<0.05)$ after 48 hours and 72 hours hypoxia, respectively (Fig. 3b, c). In 769-P cells exposed to hypoxia for 48-72 hours, eEF2K was not even detectable (Fig. 3c). These results suggest that hypoxic stress is a strong inhibitory factor to eEF2K and further support that the up-regulation of ERK1/2 is a specific response of renal cells to hypoxic insults and that the response of p38 to hypoxia varies in different renal cells.

\section{Greater tolerance of NRK-52E cells to hypoxia vs. two other kinds of renal cells}

Under hypoxic conditions, as shown in Fig. 4a, ERK1/2 was upregulated in all renal cells except for HK-2 and 769-P cells after 72 hours hypoxia with serious cell injury, while p38 was upregulated only in NRK-52E cells. In contrast, eEF2K expression was largely inhibited in all cells. Under microscopy, the morphology of NRK-52E cells showed no appreciable changes compared to the control for up to 72 hours hypoxia (Fig. 4b). However, there were different manifestations in HK-2 and 769-P cells in terms of their tolerance to hypoxia. After exposure to hypoxia for 24 hours, no visible changes appeared, in comparison with corresponding normoxia groups. After 48 hours hypoxia, however, some HK-2 cells began to shrink, dissolve and disappear with the surrounding connections, and some of them floated in the culture medium (Fig. 4b, panels 1 and 2). Greater damage was seen in 769-P cells (Fig. 4b, panels 3 and 4). After 72 hours hypoxia, almost all HK-2 and 769-P cells were floating in agglomerates (Fig. 4b, panel 5-8). In order to further validate the observation under microscopy, we analyzed cell numbers under normoxia as well as under hypoxia. As shown in Fig. 4c, compared with the control cell, NRK-52E cell numbers were not statistically different from those under hypoxia, but the numbers of HK-2 and 769-P cells were significantly reduced after hypoxia for 72 hours $(\mathrm{p}<0.05)$. These appearances indexed that NRK-52E cells are much more tolerant to hypoxic stress than HK-2 and 769-P cells.

\section{Discussion}

In the present study, we demonstrated that under the same hypoxic condition, 1) phosphorylated ERK1/2 was up-regulated in all renal cells; 2) phosphorylated p38 was markedly increased in NRK-52E after hypoxia for 24-72 hours, while there was no appreciable change in HK-2 and 769-P cells exposed to hypoxia for 24-48 hours and significantly decreased in these cells after 72 hours hypoxia; 3) hypoxia markedly downregulated eEF2K expression in all three cells; and 4) NRK-52E cells had no visible injury after 72 hours hypoxia, while HK-2 and 769-P cells were mostly damaged under the same conditions.

Hypoxia is a common clinical condition with a strong effect on both normal and abnormal cells including tumor cells. In fact, it is a common characteristic of pathophysiology in many types of solid tumors, including renal cancer and plays critical roles in the development and progression of cancers. As an adaptive response to hypoxic stress, hypoxic tumor cells activate several survival pathways to carry out their essential biological processes in different ways [20-22]. The present study strongly demonstrate that both ERK1/2 and p38 are very sensitive to hypoxic stress in both normal and tumor kidney cells. 
MAPK signal pathways are among the most widespread mechanisms for eukaryotic cell regulation. By coordinating activation of gene transcription, protein synthesis, cell cycle machinery, cell death, and cell differentiation, these pathways exert a profound effect on cell physiology, including proliferation, differentiation, apoptosis and survival [23-25]. Accordingly, MAPK pathways contribute to the progression and pathology of diverse human diseases with renal disease being no exception. However, the regulation of MAPK pathways may be very different in different cells. Indeed, here we show that three types of kidney cells have different responses to environmental stress. Our previous studies [14] have shown that the phosphorylation of both ERK1/2 and p38 is largely up-regulated in the NRK-52E cells, a kind of normal rat kidney cell, in response to hypoxic stress. Interestingly, p38 up-regulation was absent in human kidney cells, in both normal and tumor cells, under the same hypoxic condition. Therefore, we caution readers that it is important to carefully interpret the data and make comparisons of the results among different kidney cells and between the animal and human models.

It is very interesting to note that NRK-52E cells with the up-regulation of both ERK1/2 and p38 are much more tolerant to hypoxic stress than the 769-P and HK-2 cells without $\mathrm{p} 38$ up-regulation. The ERK1/2 phosphorylation cascade is important in intracellular signaling. Although, there are some opposing views, most of the previous studies show that ERK1/2 activation is beneficial for the survival of kidney cells. For example, Chen et al. indicated that HO-1 induced ERK1/2 activation enhances renal tubular recovery and subsequently prevents further renal injury [26]. Fogelgren et al. demonstrated that sec10 over-expression increased ERK1/2 phosphorylation and cell recovery from oxidative injury [27]. In general, p38 has an opposite function to that of ERK1/2 [28-30]. An inhibition of the p38 pathway can prevent a loss of renal function in diseased rat and human kidneys [31]. Mei et al. showed that by inhibiting p38, Peroxiredoxin 1 alleviates the $\mathrm{H}_{2} \mathrm{O}_{2}$-induced apoptosis in NRK-52E cells [32]. The same is true for tumor cells. Several vivo and vitro studies [33-36] have shown that in renal tumors, ERK1/2 contributes to proliferation and metastasis, while p38 promotes apoptosis. For example, Suzuki et al. indicated that in 769-P and 786-0 cells, inhibiting the ERK1/2 pathway induces apoptosis [37]. Kim et al. indicated that p38 MAPK appeared to independently mediate IL-4 induced growth inhibition and cellular senescence in some human RCC cell lines [38]. If the beneficial role of ERK1/2 is true, its up-regulation in all three cells is very likely an adaptive regulation against hypoxic insults. However, it is unclear at this stage why the 769-P and HK-2 cells that had no p38 up-regulation in hypoxia are more vulnerable than NRK-52E cells that had p38 up-regulation, if it is an injury factor as shown in many previous studies [31, 32].

To ascertain the specificity of the above changes, we further detected a non-MAPK kinase, eEF2K from the same cell samples. This kinase, also known as $\mathrm{Ca}(2+) /$ calmodulindependent protein kinase III, is a negative modulator of protein synthesis and can control the rate of translation elongation through its phosphorylation of eukaryotic elongation factor- 2 (eEF2) (the only known substrate) or its own autophosphorylation at multiple sites [39, 40]. EEF2K is over-expressed in different types of malignancies, such as pancreatic cancer [41], glioblastoma [42], and breast cancer [43]. In our previous work, we observed that eEF2K expression was increased in renal cell cancer [44]. Its activity is sensitive to hypoxia, as well as nutrient deprivation and DNA damage [45-48]. Since hypoxia can severely decrease cellular ATP levels, it is reasonable to assume that eEF2K activity may be increased by hypoxia to suppress the rate of elongation in order to down-regulate high-energy processes including protein synthesis for energy re-balance. However, we found that hypoxia gravely inhibits eEF2K expression in all NRK-52E, HK-2 and 769-P cells, suggesting that it is vulnerable to hypoxic stress. On the other hand, this notion suggest that the differential regulation of ERK1/2 and p38 is a specific, rather than a general, cell response to hypoxic stress.

In summary, the kidneys are extremely sensitive to oxygen insufficiency. To respond and adapt to decreases in renal oxygenation, renal cells evolve in a variety of ways under physiologic and under pathologic conditions. In addition, these changes have wide-ranging implications for the pathogenesis and treatment of renal diseases [49]. From amongst many 


\section{Cellular Physiology Cell Physiol Biochem 2018;46:1483-1492 \begin{tabular}{ll|l} 
and Biochemistry Published online: April 24, 2018 & $\begin{array}{l}\text { (c) } 2018 \text { The Author(s). Published by S. Karger AG, Basel } \\
\text { www.karger.com/cpb }\end{array}$
\end{tabular}}

Shi et al.: A Major Difference in eEF2K vs. MAPK Responses to Hypoxia

bsignal pathways, MAPKs (especially ERK1/2 and p38) play a critical role in renal cell response to hypoxic stress. ERK1/2 may be up-regulated in different renal cells to overcome the hypoxic insults, while p38 as well as eEF2K behave differently depending on cell types and many other factors. In general, p38 is not up-regulated in human normal and tumor cells (HK-2 and 769-P cells), unlike in rat normal cells (NRK-52E cells), while eEF2K is largely down-regulated in all these kidney cells. These findings help us better understand the integrative perspective on renal pathophysiology in hypoxic conditions.

\section{Acknowledgements}

This work was partially supported by Shanghai Key Laboratory of Acupuncture Mechanism and Acupoint Function (14DZ2260500), the National Natural Science Foundation of China (81590953, 81574053, 81303027), and Science and Technology Commission of Shanghai Municipality (15441903800).

The funders had no role in study design, data collection and analysis, decision to publish, or preparation of the manuscript.

\section{Disclosure Statement}

No conflict of interest exists.

\section{References}

1 Haase VH: Oxygen sensors as therapeutic targets in kidney disease. Nephrol Ther 2017;13 Suppl 1:S29-S34.

2 Layton AT: Recent advances in renal hypoxia: Insights from bench experiments and computer simulations. Am J Physiol Renal Physiol 2016;311:F162-165.

-3 Osaki LH, Gama P: Mapks and signal transduction in the control of gastrointestinal epithelial cell proliferation and differentiation. Int J Mol Sci 2013;14:10143-10161.

4 Lei YY, Wang WJ, Mei JH, Wang CL: Mitogen-activated protein kinase signal transduction in solid tumors. Asian Pac J Cancer Prev 2014;15:8539-8548.

5 Peti W, Page R: Molecular basis of map kinase regulation. Protein Sci 2013;22:1698-1710.

6 Somensi N, Brum PO, de Miranda Ramos V, Gasparotto J, Zanotto-Filho A, Rostirolla DC, da Silva Morrone M, Moreira JCF, Pens Gelain D: Extracellular hsp70 activates erk1/2, nf-kb and pro-inflammatory gene transcription through binding with rage in a549 human lung cancer cells. Cell Physiol Biochem 2017;42:2507-2522.

7 Munshi A, Ramesh R: Mitogen-activated protein kinases and their role in radiation response. Genes Cancer 2013;4:401-408.

-8 Pacchioni D, Negro F, Chiaberge E, Rizzetto M, Bonino F, Bussolati G: Detection of hepatitis delta virus rna by a nonradioactive in situ hybridization procedure. Hum Pathol 1992;23:557-561.

-9 Banerjee S, Bhattacharjee P, Chakraborty J, Panda AK, Bandyopadhyay A, Banik SK, Sa G: Curcumin shifts ras-induced pro-proliferative mek/erk-signaling toward pro-apoptotic p38mapk/jnk1-signaling, triggering p53 activation and apoptosis. J Biol Chem 2017

10 Guyton KZ, Liu Y, Gorospe M, Xu Q, Holbrook NJ: Activation of mitogen-activated protein kinase by h2o2. Role in cell survival following oxidant injury. J Biol Chem 1996;271:4138-4142.

11 Takeda K, Ichijo H: Neuronal p38 mapk signalling: An emerging regulator of cell fate and function in the nervous system. Genes Cells 2002;7:1099-1111.

12 Legos JJ, McLaughlin B, Skaper SD, Strijbos PJ, Parsons AA, Aizenman E, Herin GA, Barone FC, Erhardt JA: The selective p38 inhibitor sb-239063 protects primary neurons from mild to moderate excitotoxic injury. Eur J Pharmacol 2002;447:37-42. 


\section{Cellular Physiology Cell Physiol Biochem 2018;46:1483-1492 \begin{tabular}{l|l} 
and Biochemistry & DOI: 10.1159/000489188 \\
Published on 2018 The Author(s). Published by S. Karger AG, Basel \\
www.karger.com/cpb
\end{tabular}

13 Yu X, Li T, Liu X, Yu H, Hao Z, Chen Y, Zhang C, Liu Y, Li Q Mao M, Zhu D: Modulation of pulmonary vascular remodeling in hypoxia: Role of 15-lox-2/15-hete-mapks pathway. Cell Physiol Biochem 2015;35:20792097.

14 Luo F, Shi J, Shi Q He X, Xia Y: Erk and p38 upregulation versus bcl-6 downregulation in rat kidney epithelial cells exposed to prolonged hypoxia. Cell Transplant 2017

15 Luo F, Shi J, Shi Q Xu X, Xia Y, He X: Mitogen-activated protein kinases and hypoxic/ischemic nephropathy. Cell Physiol Biochem 2016;39:1051-1067.

-16 Ma MC, Qian H, Ghassemi F, Zhao P, Xia Y: Oxygen-sensitive \{delta\}-opioid receptor-regulated survival and death signals: Novel insights into neuronal preconditioning and protection. J Biol Chem 2005;280:1620816218.

17 Cheng Y, Ren X, Zhang Y, Patel R, Sharma A, Wu H, Robertson GP, Yan L, Rubin E, Yang JM: Eef-2 kinase dictates cross-talk between autophagy and apoptosis induced by akt inhibition, thereby modulating cytotoxicity of novel akt inhibitor mk-2206. Cancer Res 2011;71:2654-2663.

18 Qiu Q, Xiong W, Yang C, Dai X, Dan X, Yang Z, Jiao Y, Xiang Y, Liu G, Hardy P: Lymphocyte-derived microparticles induce apoptosis of airway epithelial cells through activation of p38 mapk and production of arachidonic acid. Apoptosis 2014;19:1113-1127.

19 Kenney JW, Sorokina O, Genheden M, Sorokin A, Armstrong JD, Proud CG: Dynamics of elongation factor 2 kinase regulation in cortical neurons in response to synaptic activity. J Neurosci 2015;35:3034-3047.

-20 Schodel J, Grampp S, Maher ER, Moch H, Ratcliffe PJ, Russo P, Mole DR: Hypoxia, hypoxia-inducible transcription factors, and renal cancer. Eur Urol 2016;69:646-657.

21 Masoud GN, Li W: Hif-1alpha pathway: Role, regulation and intervention for cancer therapy. Acta Pharm Sin B 2015;5:378-389.

22 Talks KL, Turley H, Gatter KC, Maxwell PH, Pugh CW, Ratcliffe PJ, Harris AL: The expression and distribution of the hypoxia-inducible factors hif-1alpha and hif-2alpha in normal human tissues, cancers, and tumorassociated macrophages. Am J Pathol 2000;157:411-421.

23 Kyriakis JM, Avruch J: Mammalian mitogen-activated protein kinase signal transduction pathways activated by stress and inflammation. Physiol Rev 2001;81:807-869.

24 Kim EK, Choi EJ: Compromised mapk signaling in human diseases: An update. Arch Toxicol 2015;89:867882.

25 Sun P, Sun X, Zhao W, Ren M, Zhang C, Wang Z, Xu W: Lemur tyrosine kinase-3 suppresses growth of prostate cancer via the akt and mapk signaling pathways. Cell Physiol Biochem 2017;42:2582-2592.

26 Chen HH, Lu PJ, Chen BR, Hsiao M, Ho WY, Tseng CJ: Heme oxygenase-1 ameliorates kidney ischemiareperfusion injury in mice through extracellular signal-regulated kinase 1/2-enhanced tubular epithelium proliferation. Biochim Biophys Acta 2015;1852:2195-2201.

-27 Fogelgren B, Zuo X, Buonato JM, Vasilyev A, Baek JI, Choi SY, Chacon-Heszele MF, Palmyre A, Polgar N, Drummond I, Park KM, Lazzara MJ, Lipschutz JH: Exocyst sec10 protects renal tubule cells from injury by egfr/mapk activation and effects on endocytosis. Am J Physiol Renal Physiol 2014;307:F1334-1341.

-28 di Mari JF, Davis R, Safirstein RL: Mapk activation determines renal epithelial cell survival during oxidative injury. Am J Physiol 1999;277:F195-203.

-29 Li C, Wang T, Zhang C, Xuan J, Su C, Wang Y: Quercetin attenuates cardiomyocyte apoptosis via inhibition of jnk and p38 mitogen-activated protein kinase signaling pathways. Gene 2016;577:275-280.

-30 Hung CC, Ichimura T, Stevens JL, Bonventre JV: Protection of renal epithelial cells against oxidative injury by endoplasmic reticulum stress preconditioning is mediated by erk $1 / 2$ activation. J Biol Chem 2003;278:29317-29326.

-31 Stambe C, Atkins RC, Tesch GH, Kapoun AM, Hill PA, Schreiner GF, Nikolic-Paterson DJ: Blockade of p38alpha mapk ameliorates acute inflammatory renal injury in rat anti-gbm glomerulonephritis. J Am Soc Nephrol 2003;14:338-351.

32 Mei W, Peng Z, Lu M, Liu C, Deng Z, Xiao Y, Liu J, He Y, Yuan Q Yuan X, Tang D, Yang H, Tao L: Peroxiredoxin 1 inhibits the oxidative stress induced apoptosis in renal tubulointerstitial fibrosis. Nephrology (Carlton) 2015;20:832-842.

-33 Sharma U, Pal D, Prasad R: A novel role of alkaline phosphatase in the erk1/2 dephosphorylation in renal cell carcinoma cell lines: A new plausible therapeutic target. Biochimie 2014;107 Pt B:406-409.

-34 Han TD, Shang DH, Tian Y: Docetaxel enhances apoptosis and g2/m cell cycle arrest by suppressing mitogen-activated protein kinase signaling in human renal clear cell carcinoma. Genet Mol Res 2016;15 


\section{Cellular Physiology Cell Physiol Biochem 2018;46:1483-1492 and Biochemistry Published online: April 24, $2018 \quad \begin{aligned} & \text { DOI 1018 } 2018 \text { The Author(s). Published by S. Karger AG, Basel } \\ & \text { www.karger.com/cpb }\end{aligned}$}

Shi et al.: A Major Difference in eEF2K vs. MAPK Responses to Hypoxia

-35 Miyazaki A, Miyake H, Fujisawa M: Molecular mechanism mediating cytotoxic activity of axitinib in sunitinib-resistant human renal cell carcinoma cells. Clin Transl Oncol 2016;18:893-900.

-36 Fang Z, Tang Y, Fang J, Zhou Z, Xing Z, Guo Z, Guo X, Wang W, Jiao W, Xu Z, Liu Z: Simvastatin inhibits renal cancer cell growth and metastasis via akt/mtor, erk and jak2/stat3 pathway. PLoS One 2013;8:e62823.

-37 Suzuki K, Mizuno R, Suenaga K, Teruya T, Tanaka N, Kosaka T, Oya M: Bisebromoamide, an extract from lyngbya species, induces apoptosis through erk and mtor inhibitions in renal cancer cells. Cancer Med 2013;2:32-39.

-38 Kim HD, Yu SJ, Kim HS, Kim YJ, Choe JM, Park YG, Kim J, Sohn J: Interleukin-4 induces senescence in human renal carcinoma cell lines through stat6 and p38 mapk. J Biol Chem 2013;288:28743-28754.

39 Fu LL, Xie T, Zhang SY, Liu B: Eukaryotic elongation factor-2 kinase (eef2k): A potential therapeutic target in cancer. Apoptosis 2014;19:1527-1531.

40 Ryazanov AG: Elongation factor-2 kinase and its newly discovered relatives. FEBS Lett 2002;514:26-29.

-41 Zhang Y, Cheng Y, Zhang L, Ren X, Huber-Keener KJ, Lee S, Yun J, Wang HG, Yang JM: Inhibition of eef-2 kinase sensitizes human glioma cells to trail and down-regulates bcl-xl expression. Biochem Biophys Res Commun 2011;414:129-134.

42 Wu H, Yang JM, Jin S, Zhang H, Hait WN: Elongation factor-2 kinase regulates autophagy in human glioblastoma cells. Cancer Res 2006;66:3015-3023.

43 Parmer TG, Ward MD, Yurkow EJ, Vyas VH, Kearney TJ, Hait WN: Activity and regulation by growth factors of calmodulin-dependent protein kinase iii (elongation factor 2-kinase) in human breast cancer. Br J Cancer 1999;79:59-64.

44 Shi Q Xu X, Liu Q, Luo F, Shi J, He X: Microrna-877 acts as a tumor suppressor by directly targeting eef2k in renal cell carcinoma. Oncol Lett 2016;11:1474-1480.

-45 Gills JJ, Lopiccolo J, Dennis PA: Nelfinavir, a new anti-cancer drug with pleiotropic effects and many paths to autophagy. Autophagy 2008;4:107-109.

46 Leprivier G, Remke M, Rotblat B, Dubuc A, Mateo AR, Kool M, Agnihotri S, El-Naggar A, Yu B, Somasekharan SP, Faubert B, Bridon G, Tognon CE, Mathers J, Thomas R, Li A, Barokas A, Kwok B, Bowden M, Smith S, Wu X, Korshunov A, Hielscher T, Northcott PA, Galpin JD, Ahern CA, Wang Y, McCabe MG, Collins VP, Jones RG, Pollak M, Delattre O, Gleave ME, Jan E, Pfister SM, Proud CG, Derry WB, Taylor MD, Sorensen PH: The eef2 kinase confers resistance to nutrient deprivation by blocking translation elongation. Cell 2013;153:10641079.

47 Kenney JW, Moore CE, Wang X, Proud CG: Eukaryotic elongation factor 2 kinase, an unusual enzyme with multiple roles. Adv Biol Regul 2014;55:15-27.

48 Zheng Q, Ye J, Cao J: Translational regulator eif2alpha in tumor. Tumour Biol 2014;35:6255-6264.

49 Haase VH: Mechanisms of hypoxia responses in renal tissue. J Am Soc Nephrol 2013;24:537-541. 